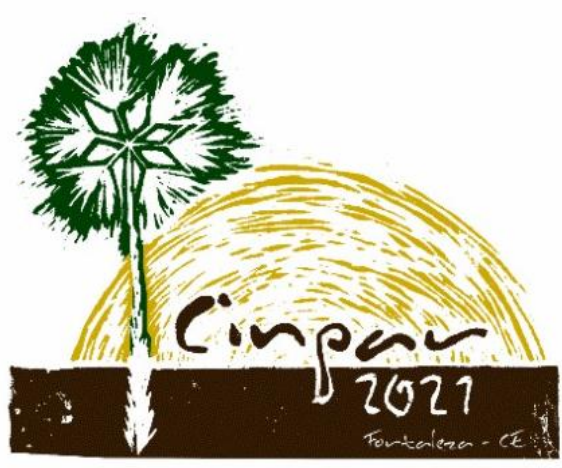

XVII Congresso Internacional sobre Patologia e

Reabilitação das Construções

XVII Congreso Internacional sobre Patología y Rehabilitación de las Construcciones

XVII International Conference on Pathology and Constructions Rehabilitation

FORTALEZA (Brasil), 3 a 5 de junho de 2021

https://doi.org/10.4322/CINPAR.2021.064

\title{
Patologia em Imóveis Alugados na Zona Leste do Município de Teresina - Piauí
}

\section{Pathology in Leased Properties in the East Zone of the Municipality of Teresina - Piaui}

\author{
Andrea Alves da Silva ${ }^{1}$, Cicero Romário de Souza ${ }^{1}$, Pablo Juan Lopes e Silva Santos ${ }^{2}$, \\ Rebeka Manuela Lobo Sousa ${ }^{2}$, Sávio Torres Melo ${ }^{1}$ \\ ${ }^{1}$ Centro Universitário do Piauí (UNIFAPI), Teresina - Piauí, Brasil, Departamento de Engenharia Civil, \\ andreaalves1x@gmail.com, cicero12romario@gmail.com, savio.melo@hotmail.com \\ ${ }^{2}$ Instituto Federal do Piauí (IFPI), Teresina - Piauí, Brasil, Departamento de Engenharia Civil, \\ pablojuan.engenhariacivil@gmail.com, rebekamanuela28@gmail.com
}

\begin{abstract}
Resumo: As manifestações patológicas causam diversos transtornos para os usuários das edificações, nos imóveis alugados não é diferente, pois geram problemas para o usuário (locatário), o proprietário (locador) e a administradora do imóvel, esse trabalho tem como finalidade procurar entender uma das maiores dificuldades encontradas dentro das imobiliárias o setor de vistoria a devolução do imóvel alugado. Com o objetivo de identificar, caracterizar e correlacionar as principais patologias apresentadas nas vistorias de saída dos imóveis alugados na zona leste de Teresina - PI. A qualidade dos dados foi fundamental os procedimentos de análise da pesquisa, foram realizados uma pesquisa documental no software Devolus Vistoria. Para evitar ao máximo esses tipos de problemas, a qualidade dos dados se tornou fundamental para determinar os procedimentos de análise para a pesquisa, os imóveis foram escolhidos pelo critério de melhor localização no município, região mais procurada. A pesquisa foi importante para compreender esses fatores determinantes para uma devolução do imóvel de forma tranquila sem transtornos as partes envolvidas. No trabalho foram observadas as principais patologias encontradas nas edificações e suas possíveis causas. Diante dos documentos analisados na pesquisa observou que a principal manifestação patológica ficou dentro da categoria umidade, os vazamentos em sistemas de instalação hidráulica da edificação e a principal causa das manifestações patológicas foram à má utilização pelo usuário e falta de manutenção periódica nos imóveis alugados. A manutenção preventiva é de extrema importância para manter o bom desempenho do imóvel, prolongando a vida útil da edificação e mantendo a valorização do imóvel para a próxima locação.
\end{abstract}

Palavras-chave: Patologias. Vistorias. Devolus Vistoria. Manutenção.

Abstract: The pathological manifestations cause several disturbances for the users of the buildings, in rented properties it is not different, because they generate problems for the user (lessee), the owner (lessor) and the property manager, this work aims to try to understand a of the biggest difficulties found within the real estate companies the inspection sector the return of the rented property. In order to identify, characterize and correlate the main pathologies presented in surveys of rented properties on the east side of Teresina - PI. The quality of the data was fundamental in the research analysis procedures, a documentary research was carried out in the Devolus Vistoria software. To avoid these types of problems as much as possible, the quality of the data became essential to determine the analysis procedures for the research, the properties were chosen by the criterion of best location in the municipality, the most sought after region. The research was important to understand these determining factors for a smooth return of the property without disturbing the parties involved. At work, the main pathologies found in buildings and their possible causes were observed. In view of the documents analyzed in the research, he observed that the main pathological manifestation was within the humidity category, the leaks in the building's hydraulic installation systems and the main cause of the pathological manifestations were the misuse by the user and the lack of periodic maintenance in the rented properties. Preventive maintenance is extremely important to maintain the good performance of the property, extending the useful life of the building and maintaining the property's valuation for the next location.

Keywords: Pathologies. Surveys. Devolus Inspection. Maintenance. 


\section{Introdução}

A construção civil apresenta uma grande importância para a economia como um todo pela capacidade de gerar efeitos na produção, na renda e no emprego sendo considerado um setor chave para o desenvolvimento de um país. O mercado imobiliário corresponde ao setor da economia, onde ocorre à negociação de imóveis, seja ela compra, venda ou aluguel.

A indústria da construção civil e imobiliária tem aprimorado os processos construtivos e diversas ferramentas de gestão imobiliária, gerenciamento de riscos e controle de processos, com o intuito de aperfeiçoar o ramo imobiliário fornecendo subsídios à tomada de decisão por parte dos diversos agentes desse mercado. Dentre as ferramentas disponíveis e em fase de ampliação de utilização estão as vistorias. Segundo a NBR 14653-1 vistoria corresponde a "constatação local de fatos, mediante observações criteriosas em um bem e nos elementos e condições que o constituem ou o influenciam" as quais importantes elementos para soluções controvérsias na construção civil, evitando que estas se transformem em litígios judiciais, sempre onerosos e desgastantes.

As vistorias imobiliárias (figura 1) realizadas nas diversas fases da vida de um imóvel, desde o planejamento até a comercialização, entrega, após a entrega se torna fundamental para o diagnóstico de patologias e recuperação das edificações.

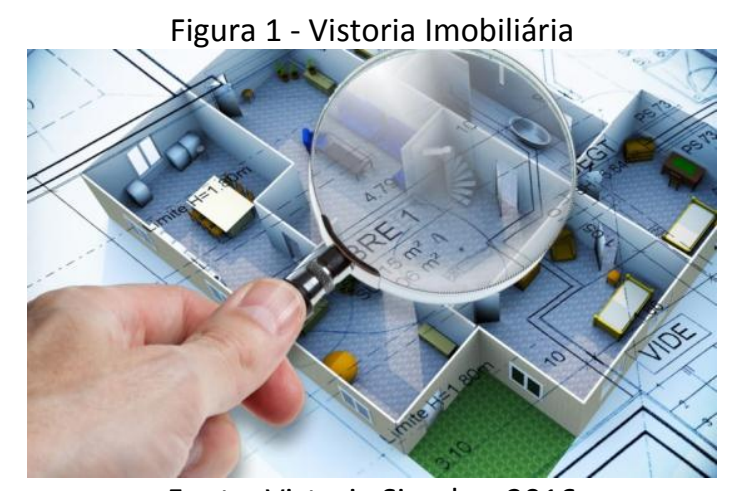

Fonte: Vistoria Simples, 2016

Além das decorrentes falhas construtivas que ocasionam as patologias, surge outro fator que deve ser levado em consideração a vida útil do imóvel, de acordo com a NBR 15575, a vida útil de uma edificação corresponde a uma medida temporal sobre sua durabilidade, ou seja, o tempo em que esses elementos conseguem desempenhar as funções ou atividades que as quais foram projetadas.

A locação de um imóvel acontece quando locatário, mediante pagamento do aluguel ao locador, fica com a posse do imóvel pelo tempo estipulado informado ao contrato realizado junto ao proprietário do imóvel ou uma administradora de imóveis (imobiliária) e quando for determinada a entrega do imóvel, se realiza uma vistória para verificar suas condições, para saber se está da forma entregue ou teve alguma alteração (patologia).

Muitas das patologias encontradas por meios de vistorias relacionam ao tempo de uso do imóvel locado, uso inadequado, vida útil e falta de manutenção preventiva. Segundo Sousa et al. (2018), a manutenção das edificações vem sendo desenvolvida em virtude da conscientização dos superiores e usuários, decorrente da necessidade da realização desses serviços na apresentação das preservações das construções e aumento da vida útil da edificação.

De acordo com Oliveira (2013), a patologia pode ser entendida como a parte da engenharia que estuda os sintomas, os mecanismos, as causas e origens dos defeitos nas edificações, ou seja, um estudo que compõem o diagnóstico do problema. Há diversas as patologias existentes e podem ter muitas causas, algumas naturais e surgem devido ao tempo de uso das edificações, outras ocorrem em função de problemas de execução, uso de materiais sem qualidade ou por falta de um projeto técnico adequado. As manifestações patológicas encontradas nas edificações podem se dividir em grupos com suas ramificações e especificações, como: Instalações hidrossanitárias, Alvenaria, Impermeabilização, etc. 
Por isso, a relevância dessa pesquisa a qualquer contrato, seja de locação ou venda, pois a importância de destacar essas vistorias em qualquer imóvel se torna fundamental, não pelo fato de ser um serviço cansativo ou caro, mas necessário tanto para a própria imobiliária como aos clientes que fazem parte dela, tornando assim uma experiência produtiva a ambos.

\section{Patologias}

Patologia é uma ciência formada por um conjunto de teorias que serve para explicar o mecanismo e a causa da ocorrência de determinada manifestação patológica (OLIVEIRA; OLIVEIRA; ARAÚJO, 2019). As patologias na engenharia civil se originam por erros que ocorrem durante o processo de uma ou mais das atividades que fazem parte da vida útil de uma edificação esses erros podem acontecer no planejamento da edificação, nos projetos, execução, na utilização e na manutenção do imóvel.

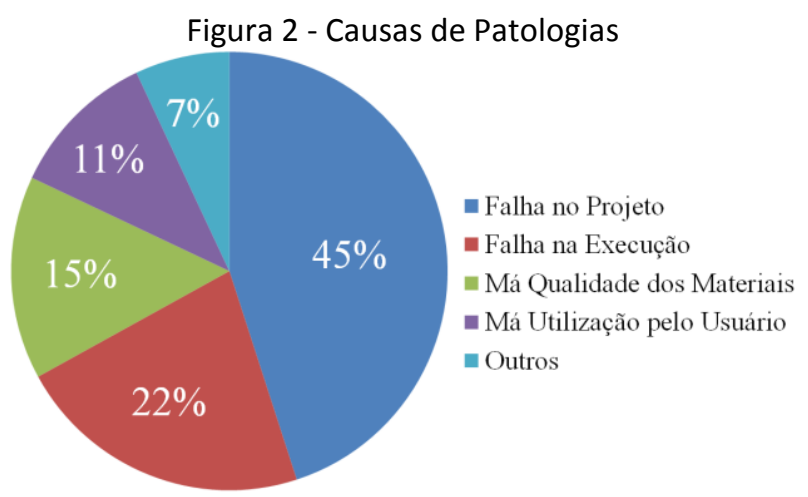

Fonte: IBAPE/RS

A ABNT NBR 15575:2013, determina as especificações que precisam ser seguidos no processor de projetos e é responsabilidade do projetista caracterizar todo o projeto, informando em cada tipo de projeto as informações fundamentais necessárias para uma boa performance na obra. Para uma execução sem muitas surpresas desagradáveis o profissional deve examinar as condições do solo, as quais a edificação se sujeitará. Algumas falhas ocorrem durante esse processo de planejamento nos estudos preliminares.

Tejo (2018) relacionou algumas das falhas em projetos que geram prejuízos patológicos a edificação. Projetos mal elaborados ou incompletos; Falta de detalhes construtivos; Incompatibilidade de diferentes projetos; Informações erradas ou insuficientes como projetos não cotados. Os detalhes construtivos são essenciais para a concepção, facilitam a execução no canteiro de obras, um projeto claro e bem elaborado é a alma edificação.

Na execução os problemas mais recorrentes que acarretam patologias são o uso de materiais de qualidade duvidosa, erros na dosagem do material, a falta de qualificação da mão de obra, assim como o cumprimento das especificações de projeto. Para Oliveira (2013), muitas condutas poderiam ser adotadas para evitar patologias nas edificações, havendo necessidade de uma visão completa e profunda de todo o processo construtivo.

Os problemas devido ao uso, o desgaste natural ou a falta de manutenção são uma grande parcela das patologias encontradas nas edificações isso porque é dever da construtora uma garantia de 5 anos após a edificação pronta mais os usuários devem compreender que uma edificação também tem uma vida útil e é necessário manutenção preventiva para que a vida útil desse imóvel seja prorrogada e evitar diversos tipos de problemas, o que também ocorre é que os usuários principalmente em caso de imóveis alugados na maioria das vezes eles não se preocupam com a manutenção do imóvel um dos motivos é o fato de acreditar que como o imóvel não é deles não tem essa obrigação.

A vida útil de edificação satisfatória acontece quando a mesma é projetada, construída e operadas de forma que, sob as condições ambientais esperadas, ela mantenha sua segurança, funcionalidade e a aparência aceitável durante um período de tempo razoável, Vida útil é aquela onde a estrutura conserva todas as características mínimas de funcionalidade, resistência e aspectos externos exigíveis. (OLIVEIRA, 2013). 
Segundo Lima (2015) As principais patologias encontradas nas edificações se dividem em grupos os 3 grupos que mais aparecem são Instalações hidrossanitários; Alvenaria; Impermeabilização. No grupo das Instalações hidrossanitários nas tubulações de água fria são comuns às rupturas das tubulações, pressão insuficiente que impede a água de subir de forma adequada, ou pressão exagerada que acaba danificando as tubulações, tubulação barulhenta, insuficiência no desempenho de equipamentos. Existem também as que acontecem nas tubulações de esgoto como: o mau cheiro retorna de esgotos, entupimentos, conforme o autor Vieira (2016).

De acordo com Jiménez (2009) listou alguns problemas que ocasionam os vazamentos nas tubulações: Perda de vedação hidráulica; Corrosão externa; Quebra; Corrosão interna; Falha do selo da rede de evacuação; Obstrução no tubo de drenagem da tempestade; Redução da capacidade de condução do tubo hidráulico; Sifão sanitário; Envelhecimento.

Muitas patologias são encontradas na alvenaria, como fissuras, trincas, rachaduras, quem podem ocorrer segundo (LIMA, 2015) decorrentes de Movimentações provocadas por variações térmicas e de umidade; Atuação de sobrecargas ou concentração de tensões; Deformabilidade excessiva das estruturas; Recalques diferenciados das fundações; Retração de produtos à base de ligantes hidráulicos; Alterações químicas de materiais de construção.

A falta de impermeabilização gera machas da edificação que se manifestam através da capilaridade de umidade do solo, infiltração de água decorrente de vazamentos. (SILVA,2018) cita as principais causas para o surgimento de patologias em impermeabilizações: Baixa qualidade dos materiais impermeabilizantes; Falta de impermeabilização; Escolha de materiais inadequados; Dimensionamento inadequado para o escoamento das águas pluviais; A não consideração do efeito térmico sobre a laje; Pouco caimento para o escoamento das águas; Execução inadequada da impermeabilização; Má execução das juntas; Rodapés mal executados; Acabamento mal executado no entorno de ralos; Acabamento mal executado em passagens de tubulações pela laje; Ralos quebrados; Rachaduras da platibanda; Vazamento de tubulações furadas ou rachadas; Entupimento de ralos; Ruptura da impermeabilização; Ruptura de revestimento cerâmico; Concretagem mal executada, produzindo: falhas, concreto desagregado; Formas mal executadas; Instalações das tubulações mal executadas.

As patologias encontradas em esquadrias as trincas que se formam acima das portas, quando faltou o uso da verga, portas inchadas durante o inverno e comum em áreas que apresentam umidade. As manifestações patológicas nas esquadrias também estão relacionadas com a umidade como as infiltrações nas interfaces do peitoril e infiltrações pela interface janela/alvenaria e verga (Lima, 2016).

\section{Metodologia}

A metodologia utilizada para o desenvolvimento da pesquisa teve o objetivo identificar as principais patologias encontradas nas vistorias dos imóveis alugados na zona leste de Teresina-PI, com intenção de fundamentar a importância de realizar laudos de vistorias periódicas em imóveis alugados para mapear e sugerir as devidas manutenções nos imóveis alugados.

A técnica de pesquisa utilizada foi à pesquisa documental retirada dos relatórios de laudos de vistoria de entrada e vistoria de saída de imóveis alugados. Primeiramente, foi realizada a escolha da Imobiliária para fornecer os laudos de vistoria. Dentre os critérios para a escolha da imobiliária foi à conveniência por ser o local de trabalho do pesquisador, o segundo aspecto foi o foco da imobiliária em locação de imóveis na cidade de Teresina-PI, dentre as imobiliária operantes na administração de aluguel e a grande quantidade da carteira de imóveis alugados por intermédio da imobiliária foi relevante para a pesquisa. A imobiliária contribuinte com a pesquisa optou por sistematizar as vistorias em um aplicativo de vistoria com registrado no sistema de armazenamento de dados chamado da Devolus Vistoria.

A escolha das propriedades para a pesquisa requer compreender um pouco do sistema, a fim de delimitar a quantidade e qualidade das informações existentes para a satisfação do cliente, ou seja, os imóveis escolhidos foram às prioridades dos clientes no critério de melhor localização no município de 
Teresina-PI. Diante desse procedimento de posição, a preferível corresponde à zona leste, pois ela apresenta uma grande demanda de locação.

A formação da cidade de Teresina corresponde a cinco zonas (sul, norte, central, sudeste e leste), no qual cada zona tem inúmeros bairros, diante disso para melhorar a especificação da pesquisa, se tornar mais adequado estudar a maior concentração em zona e bairro de imóveis locados. O Sistema Devolus Vistoria opera na empresa desde abril de 2018, foram escolhidos 10 imóveis com vistoria de estra e saída alugados pelo período, entre 6 meses a 18 meses.

A escolha destas propriedades corresponde à organização dos documentos de vistoria conforme mostra fotografias de todos os cômodos do imóvel e os laudos técnicos de entrada e saída, a fim de informar com exatidão as devidas patologias existentes durante esse tempo de locação. Após o acesso dos relatórios dos 10 imóveis selecionados (que apresentavam os laudos de vistoria de entrada e laudos de vistoria de saída), foram organizadas as patologias encontradas e separadas por categorias existentes, a fim de melhorar a compreensão de quais anomalias mais aparecem nos imóveis. As manifestações patológicas foram divididas em 5 grupos:

1. Patologia ocasionadas por Umidade;

2. Patologias encontradas nos Revestimentos Argamassados e Cerâmicos;

3. Patologias nas Instalações Elétricas;

4. Patologias nas Esquadrias;

5. Patologias ocasionadas por Outros Motivos.

As patologias foram divididas de acordo com Causa de Patologias, que dividiram o em 3 possíveis causas:

1. Falha na execução;

2. Má qualidade dos materiais;

3. Má utilização pelo usuário.

\section{Resultados e Discussões}

Para a obtenção dos resultados deste trabalho, foram realizadas as análises das pendencias encontradas nos documentos de vistorias de saída de 10 imóveis armazenados no sistema de armazenamento dados Devolus Vistoria alugados em uma imobiliária de Teresina Piauí, cujo objetivo era catalogar as manifestações patológicas detectadas nos laudos de vistoria e suas possíveis causas.

Observando o sistema do programa percebeu que cerca de 51\% dos imóveis cadastrados, ou seja, alugados pela imobiliária faziam parte da zona leste de Teresina-PI, é uma região com maior índice e procura por moradia na cidade por ser uma região próximos dos shoppings, faculdades, e com muito entretenimento. Na figura a seguir mostra a Relação em Porcentagem dos Imóveis alugados de acordo com cada zona da cidade.

Figura 3 - Relação em Porcentagem de Imóveis Alugados em Teresina-PI

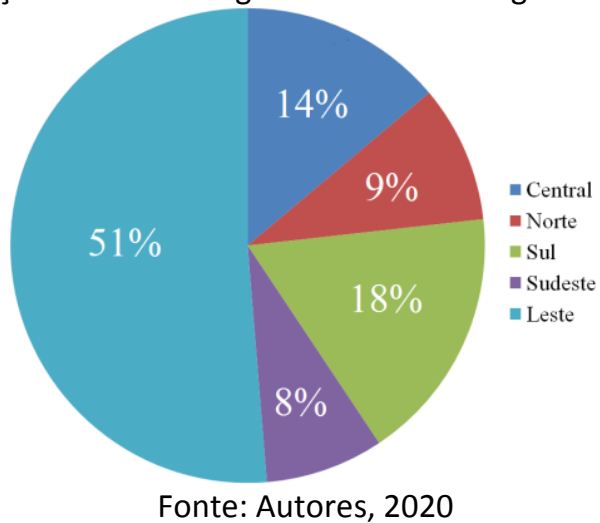

Por esse motivo optou por selecionar os imóveis da região leste, dos 10 imóveis utilizados na pesquisa foi escolhido 1 de cada bairro para um melhor para se ter um melhor aproveitamento e 
distribuição da pesquisa. De acordo com a tabela abaixo que mostra os bairros dos 10 imóveis selecionados, a data de cada vistoria realizada e o período em que permaneceu alugado o imóvel.

Tabela 1 - Intervalo das Vistorias dos Imóveis

\begin{tabular}{|c|c|c|c|c|c|}
\hline \multirow[b]{2}{*}{ Imóvel } & \multirow[b]{2}{*}{ Bairro } & \multirow{2}{*}{$\begin{array}{c}\text { Intervalo } \\
\text { (Meses) }\end{array}$} & \multicolumn{2}{|c|}{ Vistoria } & \multirow{2}{*}{$\begin{array}{c}\text { Tempo de Locação } \\
\text { (Meses) }\end{array}$} \\
\hline & & & Entrada & Saída & \\
\hline 1 & Uruguai & Até 6 meses & $26 / 10 / 2018$ & $16 / 04 / 2019$ & 6 meses \\
\hline 2 & São João & \multirow{5}{*}{ Entre 6 a 12 meses } & $14 / 05 / 2019$ & $10 / 12 / 2019$ & 7 meses \\
\hline 3 & Campestre & & 04/04/2019 & $03 / 12 / 2019$ & 8 meses \\
\hline 4 & Jockey & & $20 / 03 / 2019$ & $23 / 12 / 2019$ & 9 meses \\
\hline 5 & Planalto Ininga & & $13 / 02 / 2019$ & $18 / 12 / 2019$ & 10 meses \\
\hline 6 & Morros & & $28 / 03 / 2019$ & $28 / 01 / 2020$ & 10 meses \\
\hline 7 & São Cristóvão & \multirow{4}{*}{ Entre 12 a 18 meses } & $15 / 10 / 2018$ & $10 / 12 / 2019$ & 1 ano e 2 meses \\
\hline 8 & R. das Palmeiras & & $01 / 12 / 2018$ & $03 / 02 / 2020$ & 1 ano e 2 meses \\
\hline 9 & Santa Isabel & & $02 / 08 / 2018$ & $17 / 12 / 2018$ & 1 ano e 4 meses \\
\hline 10 & Ininga & & $01 / 08 / 2018$ & $27 / 01 / 2020$ & 1 ano e 5 meses \\
\hline
\end{tabular}

Fonte: Autores, 2020

Os períodos de locação dos imóveis documentos analisados varia entre 6 meses e 1 ano e 5 meses, em decorrência do tempo em que o programa está ativo na empresa desde abril de 2018. As vistorias foram feitas por um funcionário da empresa com o nível Técnico em Edificações, todos os cômodos foram vistoriados minuciosamente de toda a infraestrutura do imóvel, tanto da parte interna quanto externa, foram vistoriados: os sistemas elétricos, hidráulicos, as portas, as janelas, os forros, calhas, telhado, piso, o revestimento e a pintura. No aplicativo no tablet onde são tiradas as fotos que automaticamente vão para online do Sistema Devolus Vistoria.

O laudo técnico de saída foi comparado pelo vistoriador ao laudo técnico de entrada para identificar se o imóvel se encontrava com alguma pendência e assim poder ver o que poderia ser feito para reparação do mesmo para que pudesse entregar o imóvel na mesma condição que recebeu sem danos ou prejuízos ao proprietário. No quadro a seguir estão descritas as patologias encontradas nos 10 imóveis escolhidos.

A vistoria Inicial é muito importante e sua forma de ser executada pode comprometer relacionamento do inquilino com a imobiliária e consequentemente o relacionamento com o proprietário de imóvel, caso não seja bem executada deve conter um nível alto de detalhamento.

A vistoria de saída pode trazer problemas, caso a vistoria de entrada não tenha sido feita com a devida qualidade. Para que não aconteçam problemas, a vistoria realizada na entrada deve estar com o máximo de clareza em seu detalhamento e as fotos comprovando o estado do imóvel recebido. Para fazer essa verificação o vistoriador faz a comparação da vistoria de entrada com a atual situação encontrada no imóvel. As patologias encontradas nos documentos, os laudos de vistoria dos 10 imóveis analisados estão descritas na tabela a seguir.

Tabela 2 - Patologias Encontradas nas Vistorias de Saída 


\begin{tabular}{|c|c|}
\hline Imóvel & Patologias Encontradas nas Vistorias de Saída \\
\hline 1 & $\begin{array}{l}\text { Pintura do forro e das paredes; } \\
\text { Faltando o Espelho da Tomada; }\end{array}$ \\
\hline 2 & $\begin{array}{l}\text { Pinturas em geral (paredes); } \\
\text { Sifão com Vazamento; } \\
\text { Vidro Quebrado; }\end{array}$ \\
\hline 3 & $\begin{array}{l}\text { Pintura Externa e Interna; } \\
\text { Pintura de Portas e Janelas; } \\
\text { Fechadura da porta sem funcionar; } \\
\text { Chuveiro Elétrico sem funcionar; } \\
\text { Colar o canto do blindex com silicone; } \\
\text { Vazamento do Sifão; } \\
\text { Trocar as cerâmicas quebradas; }\end{array}$ \\
\hline 4 & $\begin{array}{l}\text { Faltando } 01 \text { chuveiro elétrico; } \\
\text { Faltando } 01 \text { espelho de tomada; }\end{array}$ \\
\hline 5 & $\begin{array}{l}\text { Pintura das paredes, forro, portas e janela; } \\
\text { Faltando } 01 \text { torneira na pia da cozinha; } \\
\text { Fechadura do WC social danificada; } \\
\text { Pia com sanfonado vazando; } \\
\text { Vazamento na ducha; } \\
\text { Vaso com entupimento; } \\
\text { Faltando registro da torneira no WC social; }\end{array}$ \\
\hline 6 & $\begin{array}{l}\text { Troca de } 03 \text { tomadas (02 na cozinha e } 01 \text { na suíte); } \\
\text { Pintura do apartamento e pintura do forro; } \\
\text { Porta do WC suíte com desgaste da madeira da base da porta; } \\
\text { Ducha com vazamento no WC suíte; }\end{array}$ \\
\hline 7 & $\begin{array}{l}\text { Pintura geral (paredes, forro e portas); } \\
\text { Furos na parede; } \\
01 \text { interruptor danificado com } 03 \text { tempos; } \\
\text { Trava da blindex esta solta WC escritório; } \\
\text { Porta da varanda soltando vedação; } \\
01 \text { tomada quebrada na área de serviço; } \\
\text { Inchaço na base da porta do quarto dependência; } \\
\text { Vidro do suporte quebrado no WC dependência; } \\
\text { WC dependência com entupimento; } \\
\text { Registro do wc suíte } 01 \text { vazando; } \\
\text { Porta da varanda desregulada suíte (02); } \\
\text { Torneira folgada no WC (02); } \\
\text { Vazamento no copo sifonado; } \\
\text { Suíte } 2 \text { folgado; torneira folgada no WC (02); } \\
\text { Suíte principal faltando } 01 \text { tapa sega e espelho para tomada; } \\
\text { Interruptor com defeito no closet; }\end{array}$ \\
\hline 8 & $\begin{array}{l}\text { Pintura das paredes e forro; } \\
\text { Pintura das portas; } \\
\text { Basculante da cozinha com trava desparafusada; } \\
\text { Cerâmicas quebradas na cozinha; }\end{array}$ \\
\hline 9 & $\begin{array}{l}\text { Furos na parede; } \\
\text { Vaso e Torneira vazando no WC suíte; } \\
\text { Manchas de infiltração; } \\
\text { Chuveiro com vazamento no WC social; } \\
\text { Cerâmica dos boxes manchados; } \\
\text { Peças de cerâmicas furadas e } 01 \text { quebrada na cozinha; } \\
01 \text { interruptor danificado na cozinha; } \\
\text { Pia da cozinha entupida; } \\
\text { Pintura das paredes e forro; }\end{array}$ \\
\hline 10 & Pintura (parede, forro e portas). \\
\hline
\end{tabular}

Fonte: Autores, 2020 
Foram encontradas o total de 52 patologias nos 10 imóveis. Dessas 52 pendências foram divididas em 6 tipos de manifestações patológicas existentes nos laudos de vistoria, conforme mostrado a seguir:

Figura 4 - Relação em Porcentagem de Manifestações Patológicas encontradas nos Imóveis

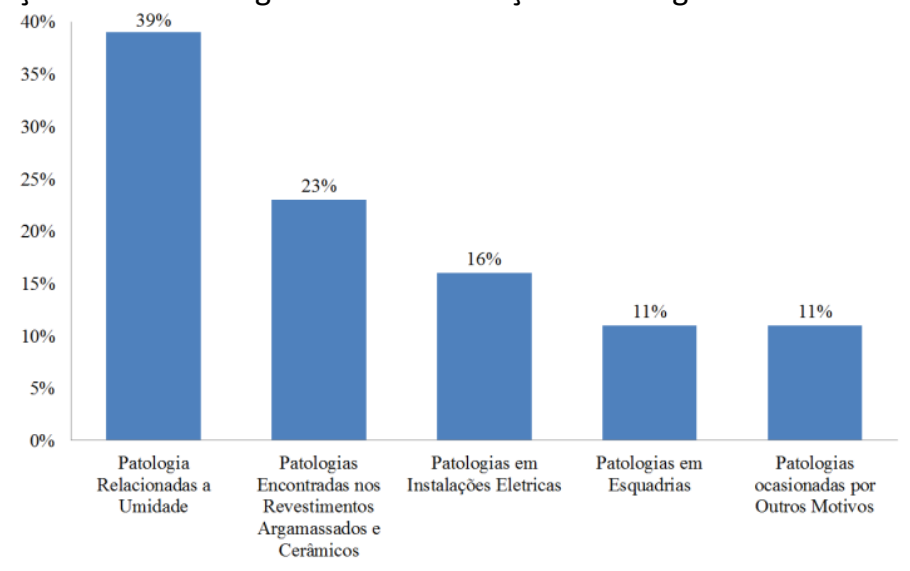

Fonte: Autores, 2020

\section{Conclusão}

A pesquisa foi importante para compreender esses fatores determinantes para uma devolução do imóvel de forma tranquila sem transtornos as partes envolvidas. As patologias em imóveis alugados geram transtorno para as 3 partes envolvidas na negociação imobiliária inquilino, o proprietário do imóvel e o a imobiliária administradora do aluguel. No trabalho foram observadas as principais patologias encontradas nas edificações e suas possíveis origens.

O interessante seria rever o sistema de manutenções, hoje realizados apenas ao sistema de manutenção corretiva para o inquilino, pois a necessidade de fazer a entrega do imóvel nas condições recebidas. $O$ aconselhado seria realizar manutenções preventiva nos imóveis no período desalugado, por parte do proprietário para manter um bom desempenho, vida útil e não sofresse a depreciação.

\section{Agradecimentos}

Agradecemos primeiro a Deus por ter nos mantido na trilha certa durante este projeto de pesquisa com saúde e forças para chegar até o final. Agradecemos também a instituição UNIFAPI pela oportunidade de cooperar com todos os nossos conhecimentos.

\section{Referências Bibliográficas}

ASSOCIAÇÃO BRASILEIRA DE NORMAS TÉCNICAS. NBR 14653-1: Avaliação de bens. Rio de Janeiro: Comitê Brasileiro de Construção Civil, 2001;

ASSOCIAÇÃO BRASILEIRA DE NORMAS TÉCNICAS. NBR 15575: Desempenho de edificações habitacionais. Rio de Janeiro. 2013;

LIMA, Bruno Santos de. Principais Manifestações Patológicas em Edificações Residenciais Multifamiliares. $66 \mathrm{f}$. Trabalho de Conclusão de Curso (Graduação) - Curso de Engenharia Civil, Centro de Tecnologia, Universidade Federal de Santa Maria, Santa Maria, 2015. Cap. 2;

OLIVEIRA, Daniel Ferreira. Levantamento de Causas de Patologias na Construção Civil. 107 f. Trabalho de Conclusão de Curso (Graduação) - Curso de Engenharia Civil, Escola Politécnica, Universidade Federal do Rio de Janeiro, Rio de Janeiro, 2013. Cap. 3;

OLIVEIRA, Maximiliano Ramos; OLIVEIRA, Tayrielle Nunes; ARAÚJO, Selma Carrijo. Patologias nas Edificações, seu Diagnóstico, e suas Causas. In: IV Colóquio Estadual de Pesquisa Multidisciplinar e II Congresso Nacional de Pesquisa Multidisciplinar, Goiás. PROEPE. Goiás: Pesquisa Unifimes, 2019. v. 1, p. 1-13;

TEJO, Fernanda de Andrade Caputo. Análise das principais patologias pós obra por um setor de assistência técnica de uma construtora de pequeno porte - Rio de Janeiro: UFRJ/Escola Politécnica. 2018. UFSC. 